SCHOLARONE $^{m}$

Manuscripts
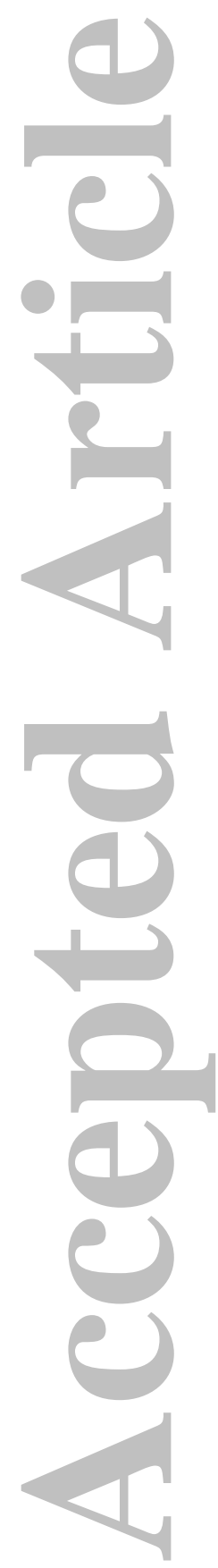

This is the author manuscript accepted for publication and has undergone full peer review but has not been through the copyediting, typesetting, pagination and proofreading process, which may lead to differences between this version and the Version record. Please cite this article as doi:10.1002/ acr.23154.

This article is protected by copyright. All rights reserved. 
Running head: Hallux valgus, by nature or nurture?

\section{Hallux valgus, by nature or nurture? A twin study}

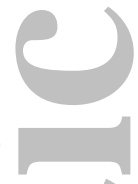

Shannon E Munteanu, B Pod (Hons), PhD ${ }^{1,2}$, Hylton B Menz, B Pod (Hons), PhD ${ }^{1,2}$, John D Wark, PhD, FRACP, MBBS ${ }^{3}$, Jemma J Christie ${ }^{4}$, Katrina J Scurrah, $\mathrm{PhD}^{5}$, Minh Bui, $\mathrm{PhD}^{5}$, Bircan Erbas ${ }^{6}$, John L Hopper, $\mathrm{PhD}^{5}$, Anita E Wluka, PhD, FRACP, MBBS ${ }^{7 凶}$

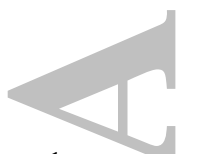

${ }^{1}$ Discipline of Podiatry, School of Allied Health, College of Science, Health and Engineering, La Trobe University, Melbourne, Victoria 3086, Australia

${ }^{2}$ La Trobe Sport and Exercise Medicine Research Centre, College of Science, Health and Engineering, La Trobe University, Melbourne, Victoria 3086, Australia

${ }^{3}$ University of Melbourne Department of Medicine, Bone and Mineral Medicine, Royal Melbourne Hospital, Parkville, Victoria 3050, Australia

${ }^{4}$ University of Melbourne, Department of Medicine, Royal Melbourne Hospital, Parkville, Victoria 3050, Australia

${ }^{5}$ Centre for Epidemiology and Biostatistics, Melbourne School of Population and Global Health, The University of Melbourne, Parkville, Victoria 3053, Australia

${ }^{6}$ Department of Public Health, School of Psychology and Public Health, College of Science, Health and Engineering, La Trobe University, Melbourne, Victoria 3086, Australia

${ }^{7}$ Department of Epidemiology \& Preventive Medicine, Monash University, Alfred Hospital, Melbourne, Victoria 3004, Australia

John Wiley \& Sons, Inc.

This article is protected by copyright. All rights reserved. 
$\triangle$ Correspondence to: Anita E Wluka: Department of Epidemiology and Preventive Medicine, Monash University, Alfred Hospital, Melbourne, Victoria 3004, Australia. Email: anita.wluka@monash.edu ; Phone: +61-3-9903 0994.

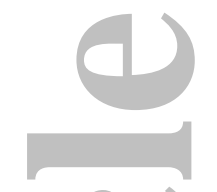

Word count, excluding title page, abstract, references, tables, figure legends: 3800

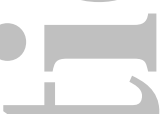

\section{ACKNOWLEDGEMENTS AND FUNDING}

This study was funded by La Trobe University, Faculty of Health Sciences and Monash University, Faculty of Medicine, Nursing and Health Sciences. HBM is currently a National Health and Medical Research Council Senior Research Fellow (ID: 1020925). AEW is the recipient of a NHMRC Career Development Fellowship (Level 2, 1063574). This research was facilitated through the Australian Twin Registry, a national resource in part supported by a Centre of Research Excellence Grant (ID: 1079102) from the National Health \& Medical Research Council. The study sponsors played no role in the study design, the collection, analysis, and interpretation of data; in the writing of the report; and in the decision to submit the article for publication. All authors, external and internal, had full access to all of the data (including statistical reports and tables) in the study and can take responsibility for the integrity of the data and the accuracy of the data analysis.

\section{COMPETING INTERESTS}

All authors have completed the Unified Competing Interest form at www.icmje.org/coi_disclosure.pdf (available on request from the corresponding author) and declare; no support from any organisation for the submitted work; no financial relationships with any organisations that might have an interest in the submitted work; no other relationships or activities that could appear to have influenced the submitted work. 


\section{AUTHORS' CONTRIBUTIONS}

SEM, HBM, JDW, BE, and AEW designed the study and obtained project funding.

JC, JDW, and JH were responsible for data collection.

SEM, BE, KJS and MB analysed data.

SEM, HBM, BE, and AEW drafted the manuscript.

JDW, JC, MB, KJS and JLH commented on the manuscript.

All authors read and approved the final manuscript before submission.
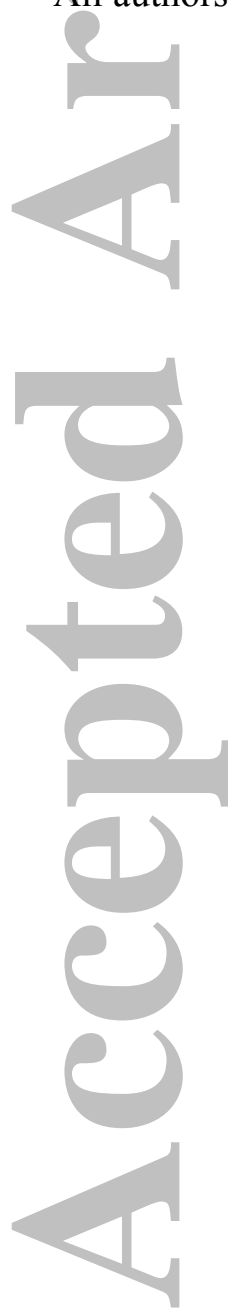

John Wiley \& Sons, Inc. 


\section{ABSTRACT}

\section{Objective:}

To evaluate the contributions of shared but unmeasured genetic and environmental factors to hallux valgus (HV).

\section{Methods:}

Between 2011-2012, 74 monozygotic (MZ) and 56 dizygotic (DZ) female twin pairs selfreported HV and putative risk factors, including footwear use across their lifespan. Estimates of casewise concordance $\left(\mathrm{P}_{\mathrm{C}}\right)$, correlation $(\rho)$ and odds ratios $(\mathrm{OR})$ were calculated, adjusting for age and other risk factors, and compared between MZ and DZ pairs using logistic regression, generalised estimating equations and a maximum likelihood-based method, respectively.

\section{Results:}

70 participants (27\%) reported $\mathrm{HV}$, with $12 \mathrm{MZ}$ and $7 \mathrm{DZ}$ pairs being concordant. After adjusting for age, twins were correlated $(\rho=0.27 ; 95 \%$ CI $0.08-0.46)$ and concordant $\left(\mathrm{P}_{\mathrm{C}}=\right.$ $0.45,95 \%$ CI $0.29-0.61$ at mean age 58 years) with no difference between MZ and DZ pairs ( $p$ $=0.7)$. $\mathrm{HV}$ was associated with regularly wearing footwear with a constrictive toe-box during the fourth decade (adjusted $\mathrm{OR}=2.73 ; 95 \% \mathrm{CI} 1.12-6.67$ ). This risk factor was correlated in $\operatorname{MZ}(\rho=0.38 ; 95 \% \mathrm{CI}=0.15-0.60)$ but not DZ $(\rho=-0.20 ; 95 \% \mathrm{CI}=-0.43-0.03)$ pairs. These correlations were significantly different $(p=0.002)$.

\section{Conclusion:}

Twins are correlated for HV but we found no evidence that this was due to shared genetic factors. We identified an environmental risk factor, footwear with a constrictive toe-box, that

John Wiley \& Sons, Inc. 
is not shared to the same extent by MZ and DZ pairs, contrary to the assumption of the classic twin model. Footwear, and possibly genetic factors and unknown shared environmental factors could contribute to developing HV.

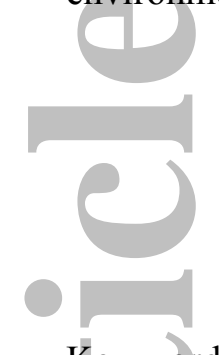

Key words: hallux valgus, twins, genetics, shoes, twin study
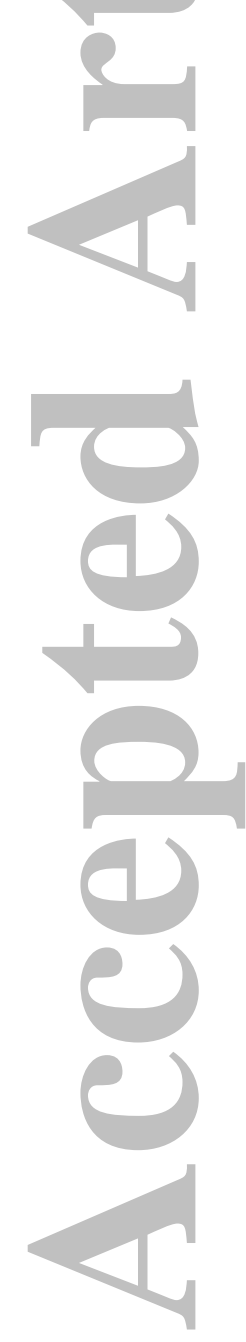

John Wiley \& Sons, Inc. 


\section{SIGNIFICANCE AND INNOVATIONS}

- Twin pairs are more concordant for hallux valgus than unrelated individuals, but

given there was no significant difference in concordance between monozygotic (MZ) and dizygotic (DZ) pairs, this could not be attributed to genetic factors. This raises the possibility that environmental risk factors shared by twins contribute to the development of hallux valgus.

- The regular use of footwear with a constrictive toe-box in the fourth decade of life was associated with increased presence of hallux valgus and is an environmental factor for this condition that was shared by MZ, but not DZ, pairs.

- Given that footwear choices are modifiable, identification of the most appropriate footwear during the life course may be able to reduce the prevalence of hallux valgus.

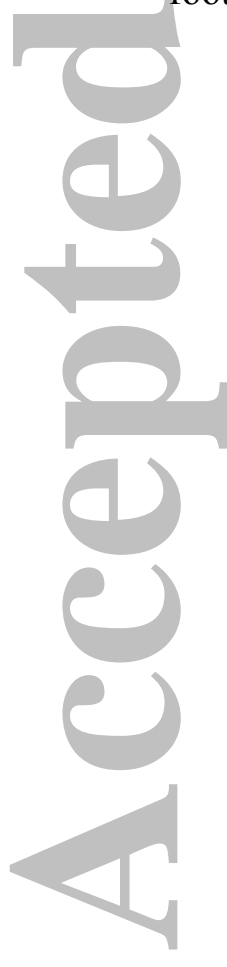

John Wiley \& Sons, Inc. 
Hallux valgus (HV) is a common condition of the foot affecting $23 \%$ of people aged $18-65$ years, and $36 \%$ of those over 65 years, and is more prevalent in females (1). It causes substantial foot pain, is related to reduced health-related quality of life (2-5), impaired balance (6), altered gait patterns (7), an increased risk of falls $(8,9)$, and is costly to treat $(10)$. $\mathrm{HV}$ is characterised by the progressive subluxation of the first metatarsophalangeal joint resulting in lateral deviation of the hallux and medial deviation of the first metatarsal. As the deformity progresses, the lateral deviation of the hallux compresses against the second toe, leading to lesser toe-deformity, keratotic lesions and difficulties finding comfortable footwear (11). This is often accompanied by a painful prominence on the medial aspect of the first metatarsal head, commonly referred to as a "bunion" (12).

(The aetiol The aetiology of $\mathrm{HV}$ is assumed to be multifactorial but is poorly understood (13). Because it evolves over decades, no prospective risk factor studies have been performed. Proposed risks can be classified as environmental or genetic $(12,14)$. Of the proposed environmental risks, footwear is considered important, particularly for females $(10,15-17)$. This is based on the prevalence of HV being lower in unshod populations and increasing when shoes are introduced into a previously-unshod population $(2,10,15)$. Footwear with an elevated heel or that is ill-fitting (too narrow/constrictive toe-box) has been associated with hallux valgus in cross-sectional studies (10, 17-21). Recently, Menz (22) found that self-reported use of footwear with a constrictive toe-box during the third and fourth decades was associated with hallux valgus in females aged 50-89 years. No association was identified for the footwear heel height. Although these findings suggest shoe width and/or heel height affect the risk of hallux valgus, their relative contributions to this requires further investigation. 
A genetic risk for HV has been proposed as $58-90 \%$ of people with HV report a family history of the condition (23-25). Pedigree studies found familial associations across three to seven generations $(25,26)$. Two recent studies, the Framingham Foot Study and a Korean twin and family member study, found familial associations that were attributed, at least partially, to unmeasured genetic factors $(27,28)$. Neither assessed the role of specific environmental factors that could be correlated in relatives.

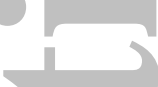

We thus hypothesised that the occurrence of $\mathrm{HV}$ in women is affected by genetic factors as well as footwear use. The primary objective of this study was to examine the familial (i.e. genetic and/or shared environmental) factors involved with HV by documenting its prevalence in monozygotic (MZ) and dizygotic (DZ) Australian female twin pairs. Under the assumptions of the classical twin model, the non-genetic factors relevant to HV variance are assumed to be shared to the same extent within MZ pairs as within DZ pairs. Therefore, a greater age-adjusted concordance/correlation for $\mathrm{MZ}$ compared with $\mathrm{DZ}$ pairs is evidence consistent with, but not proving, genetic factors influencing prevalence: a lack of difference between $\mathrm{MZ}$ and DZ pairs in within-pair concordance suggests shared environmental factors influence prevalence. The second objective of the study was to determine the association between HV and self-reported previous use of inappropriate footwear by these participants across their lifespan. The third objective was to assess the extent to which familial associations in risk factors might influence our conclusions for the first objective. Developing a better understanding of these issues may enable focused interventions to be developed to prevent HV.

\section{METHODS}

John Wiley \& Sons, Inc. 


\section{Study design and data collection}

We performed a classical twin study. A cross-sectional postal survey was conducted between April-October 2011 of female twins in Victoria, Australia. The study was approved by the Melbourne Health HREC (2010.206), and Monash University, Australia (2011000406).

\section{Participants}

Participants were 74 monozygotic (MZ) and 56 dizygotic (DZ) female twin pairs aged 31-87 years (mean $[\mathrm{SD}]$ age $=57.9[12.8])$, registered with the Australian Twin Registry and the Twin Research Program at the Royal Melbourne Hospital (Melbourne, Australia) and had participated in research investigating genetic and environmental determinants of bone health and balance performance $(29,30)$. These women were initially recruited through community outreach. They were approached by the Australian Twin Registry on behalf of the researchers

to participate in this study. The zygosity of twin pairs was determined previously $(29,30)$ through a self-report questionnaire designed by the Australian Twin Registry (31), that accurately identifies true zygosity in 95 percent of twin pairs (32). To be eligible for inclusion, participants were (i) members of a twin pair (MZ or DZ), (ii) female, and (iii) older than 30 years at the time of the postal survey. Participants were excluded if they reported inflammatory arthritis (including rheumatoid arthritis or gout), or any lower limb amputation.

\section{Medical history and anthropometric information}

Participants completed a questionnaire to obtain information concerning their age, medical history and weight $(\mathrm{kg})$. Height was determined from previous study data (29). Body mass index (BMI, $\left.\mathrm{kg} / \mathrm{m}^{2}\right)$ was calculated.

John Wiley \& Sons, Inc.

This article is protected by copyright. All rights reserved. 


\section{Assessment of $\mathrm{HV}$}

The seyerity of HV was determined by self-assessment using the Manchester scale (33), a standardised collection of four photographs which encompass the range of severity of HV. HV is graded as no deformity (grade 1), mild deformity (grade 2), moderate deformity (grade

3) or severe deformity (grade 4). Participants were asked to remove their shoes and socks and stand with weight distributed evenly on both feet, then to compare each of their feet to the scale photos and determine which image best matched each of their feet. Results for the Manchester scale were dichotomised; grades 1 and 2 were categorised as absent for HV, and grades 3 and 4 categorised as present (34). Participants were categorised as having HV if either foot had HV present. This scale has been validated against radiographic measures (34). Self-assessment of HV using this scale is reliable $(\mathrm{kappa}=0.78$, percentage agreement $=$ $95.8 \%$ ), and shows agreement with grading by a trained examiner (kappa $=0.76$, percentage agreement $=95.6 \%)(35)$. Participants reporting a history of surgery for HV were classified as having $\mathrm{HV}$.

\section{Assessment of footwear}

Past footwear use was determined by self-report using a series of drawings depicting 4 heel heights $(\mathrm{A}=$ flat, $\mathrm{B}=$ low, $\mathrm{C}=$ medium, and $\mathrm{D}=$ high $)$ and 4 toe-box shapes $(\mathrm{A}=$ very wide, $\mathrm{B}=$ wide, $\mathrm{C}=$ narrow, and $\mathrm{D}=$ very narrow) (Figure 1) (36). The heel height and degree of toe-box constriction were assessed as these footwear features have been associated with HV $(10,17-20,22)$. For each period of their life (divided into decades, commencing with 20-29 years of age), participants were asked to indicate which heel height and toe-box shape they 
wore most of the time. For each participant, data were included for the corresponding decade of life if their age was greater than the mid-point (fifth year) of that decade. The footwear features were dichotomised by classifying the two most 'inappropriate' grades (eg: for heel height, medium and high, and for toe-box shape, narrow and very narrow). The classification was determined by using expert opinion from two experienced podiatrists (SEM and HBM).

\section{(1)

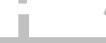 \\ Statistical analyses}

Logistic and linear regression models were used to test for differences in anthropometric and demographic characteristics between $\mathrm{MZ}$ and $\mathrm{DZ}$ participants or those with and without $\mathrm{HV}$. To accommodate the correlation structure within twin pairs for both methods, we used generalised estimating equations (GEE) to estimate parameters, the Huber-White method to estimate robust standard errors of these parameters, and Wald tests to obtain $p$-values. Logistic regression models estimated by GEE were fitted using STATA software, version 13 (StataCorp. 2013. Stata Statistical Software: Release 13. College Station, TX: StataCorp LP).

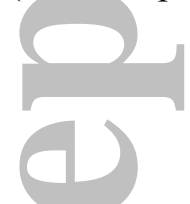

Correlations and casewise concordances were estimated to examine whether HV and its' measured risk factors were influenced by genetic and/or environmental factors. Under the assumptions of the classical twin model, non-genetic factors relevant to trait variance are shared to the same extent within MZ and DZ pairs. Therefore, a greater correlation or concordance among MZ twins than the DZ twins is evidence against a non-genetic influence hypothesis and in favour of a genetic influence hypothesis. The casewise concordance $\mathrm{P}_{\mathrm{C}}$ is the conditional probability of a twin being affected given that the co-twin is also affected and was also estimated. However, concordance depends the prevalence of the condition, which is 
expected to increase with age. In order to adjust for this, the flexible maximum likelihood method described by Hannah (37), which is based on a logistic regression model and allows concordance to depend on age (and other measured covariates), and which also provides an estimate of the "intrinsic correlation" $\rho$ independent of age, was applied to these data. Models were fitted and the likelihood maximized using the optim function in the R software package (http://www.R-project.org/). Code to fit these models is available from the authors

\section{on request.}

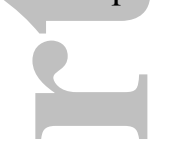

The twin odds ratio (OR), was used to examine whether HV was influenced by genetic and/or environmental factors. The twin OR is the ratio of the odds of having HV given that the cotwin has HV to the odds of having HV given that the co-twin does not have HV.

ros

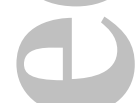

Logistic regression models fitted using GEEs were used to determine the association between the presence of $\mathrm{HV}$ and use of inappropriate footwear and other covariates. An interaction term (between zygosity and a predictor) was used to assess differences in ORs between MZ and DZ twins. The $p$-value for this term was obtained from a Wald test. The maximum likelihood method described above (37) was then applied to estimate concordances and correlations for the use of inappropriate footwear, and to adjust concordances, correlations and twin ORs of $\mathrm{HV}$ for additional covariates found to be significantly associated with presence of HV. Age was included as a covariate in all these models.

\section{RESULTS}


One hundred and fifty-two twin pairs were approached, and 130 complete pairs $(86 \% ; 74 \mathrm{MZ}$, $56 \mathrm{DZ}$ ) participated. The demographic and anthropometric characteristics of participants are shown in Table 1. The MZ and DZ twins were well matched for age and physical characteristics (all $p>0.1)$.

HV was reported by 70 participants (27\%); 42 from MZ pairs (28\%) and 28 from DZ pairs (25\%). These proportions did not differ by zygosity $(p=0.6)$. Of the participants with HV, 33 had unilateral and 37 bilateral conditions. Participants with HV were older than unaffected individuals (mean $[\mathrm{SD}]=65.6[10.0]$ versus $55.2[12.4]$ years, $p<0.001)$ but similar regarding the proportion who were obese $(\mathrm{OR}=0.44 ; 95 \% \mathrm{CI}=0.17$ to $1.14 ; p=0.09)$.

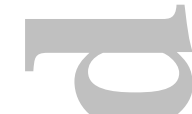

\section{Concordance and correlation of $\mathrm{HV}$ unadjusted and adjusted for age}

Of the 130 twin pairs, 19 (15\%) were concordant for HV; 12 (16\%) for MZ pairs and 7 (12.5\%) for DZ pairs. The expected concordance under no familial association was $7 \%$ (standard error $=2 \%)$. The unadjusted casewise concordance for MZ pairs was $0.57(95 \% \mathrm{CI}$ $=0.39$ to 0.75$)$ and for $\mathrm{DZ}$ pairs was $0.50(95 \% \mathrm{CI}=0.27$ to 0.73$)$. Both were greater than the expected casewise concordance under no familial association of 7\%: they did not differ significantly $(p=0.6)$. The correlation for MZ pairs was $0.40(95 \% \mathrm{CI}=0.16$ to 0.60$)$ and for DZ pairs was $0.33(95 \% \mathrm{CI}=0.06$ to 0.58$)$ : this difference was not statistically significant $(p$ $=0.7)$.

After adjusting the prevalence of HV for age, twin pairs were correlated and concordant (MZ: $\rho=0.30 ; 95 \% \mathrm{CI}=0.06$ to $0.55 ; \mathrm{DZ}: \rho=0.23 ; 95 \% \mathrm{CI}=0.08$ to 0.54$)$, but not significantly 
different $(p=0.7)$. The combined correlation was $0.27(95 \% \mathrm{CI}=0.08$ to 0.46$)$. For $\mathrm{MZ}$ pairs, concordance at the mean age of 58 years was $0.46(95 \% \mathrm{CI}=0.26$ to 0.66$)$ and for $\mathrm{DZ}$ pairs was $0.41(95 \% \mathrm{CI}=0.16$ to 0.66$)$. The estimated concordance for all twin pairs combined was $0.45(95 \% \mathrm{CI}=0.29$ to 0.61$)$.

These correlations and concordances are equivalent to an age-adjusted OR for having HV of (27

$4.27(95 \% \mathrm{CI}=1.27$ to 14.3$)$ and $3.40(95 \% \mathrm{CI}=0.74$ to 12.4$)$ for $\mathrm{MZ}$ and $\mathrm{DZ}$ pairs

respectively. These were not significantly different $(p=0.7)$.

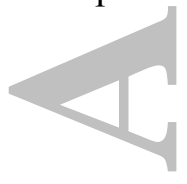

\section{Analysis of prevalence of $\mathrm{HV}$ as a function of footwear}

Unadjusted associations of HV with footwear with a narrow or very narrow toe-box and medium or high heel for MZ twins and DZ twins separately, and using combined data are presented (Table 2). HV was significantly associated with the use of footwear with a narrow or very narrow toe-box during the third and fourth decades for MZ twins ( $p=0.007$ and $<0.001$ respectively) and when combined ( $p=0.002$ and $<0.001$ respectively), and in the fourth decade for DZ twins ( $p=0.03$ ). HV was significantly associated with the use of footwear with a medium or high heel during the fourth decade for MZ twins $(p=0.03)$ and for the total sample $(p=0.02)$.

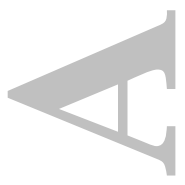

The association between HV and the use of specific footwear styles adjusted for age and BMI in the combined data using multiple logistic regression is presented (Table 3). As height was not significantly associated with HV in unadjusted analysis, it was not included in multiple regression modelling. The use of footwear with a narrow or very narrow toe-box worn during

John Wiley \& Sons, Inc.

This article is protected by copyright. All rights reserved. 
the fourth decade was the only variable significantly associated with HV when adjusted for all other factors $(p=0.028)$.

\section{Correlation of constrictive toe-box unadjusted and adjusted for age}

The risk factor for HV, narrow or very narrow toe-box worn during the fourth decade, was correlated in $\mathrm{MZ}(\rho=0.42 ; 95 \% \mathrm{CI}=0.19$ to 0.61$)$ but not $\mathrm{DZ}(\rho=-0.13 ; 95 \% \mathrm{CI}=-0.38$ to $0.13)$ pairs. These correlations differed significantly $(p=0.002)$. Adjustment for age did not substantially change the correlation in $\mathrm{MZ}(\rho=0.38 ; 95 \% \mathrm{CI}=0.15$ to 0.60$)$ or DZ pairs $(\rho=$ $-0.20 ; 95 \% \mathrm{CI}=-0.43$ to 0.03$)$.

\section{Concordance and correlation of $\mathrm{HV}$ adjusted for age and toe box}

A larger difference between $\mathrm{MZ}$ and $\mathrm{DZ}$ correlations was observed when presence of $\mathrm{HV}$ was adjusted for narrow or very narrow toe-box worn during the fourth decade, regardless of whether or not adjustment for age was made. The correlation for MZ twins $(\rho=0.35 ; 95 \%$ CI $=0.08$ to 0.62$)$ was approximately double that for DZ twins $(\rho=0.17 ; 95 \% \mathrm{CI}=0.13$ to 0.46). However, this difference was not statistically significant $(p=0.4)$.

\section{DISCUSSION}

We have confirmed a familial component to the prevalence of $\mathrm{HV}$, with about a 4-fold increased risk for having an affected twin. Our analysis suggested that this familial observation could be attributed to shared environmental factors, not to shared genes. Moreover, the use of footwear with a constrictive toe-box during the fourth decade was associated with increased prevalence of HV. Use of inappropriate footwear was correlated in

John Wiley \& Sons, Inc. 
MZ, but not DZ pairs, but when we took this into account it did not change our general conclusion.

A strong familial tendency for HV has commonly been reported, but existing evidence was largely based on pedigree studies from which it is difficult to differentiate between the effects of shared environment and shared genes (23-25). An analysis of non-twin first-degree relatives from the Framingham Foot study concluded that HV was heritable (heritability of liability 0.29 to 0.89 ), but no environmental risk factors were considered (28). Lee (27) analysed the Healthy Twin Study in Korea, concluding that variation in liability had moderate to high heritability. However, their findings relating to parent-offspring concordance were not consistent with this postulate. One interpretation of their analyses is that there is a shared environment effect, and a generational effect, due to parent-offspring concordance being less than half that for MZ twin pairs. Whilst our study confirmed a familial tendency, we were unable to identify evidence for a genetic component.

Our secondary objective was to examine the association between HV and self-reported use of inappropriate footwear, a commonly considered risk factor. We examined the association between HV and self-reported use of footwear with an excessive heel height or constrictive toe-box across participants' adult life, as these features have been associated with HV (18-20). We found that the self-reported use of footwear with a narrow or very narrow toe-box during the fourth decade was associated with an increased prevalence of $\mathrm{HV}(\mathrm{OR}, 95 \% \mathrm{CI}=2.73$, 1.12 to 6.67$)$, suggesting a role for footwear with a narrow or very narrow toe-box in the aetiology of HV. In contrast, the self-reported use of footwear with a medium or high heel 
was not independently associated with an increased prevalence of HV once the use of footwear with narrow or very narrow toe-box was accounted for.

Previous cross-sectional studies have suggested an association between HV and footwear that has a constrictive toe-box/inadequate width $(18,19)$, or an excessive heel height $(17,19-21)$.

The relative contribution of these two features across each decade of life has not been The relati thoroughly investigated. A recent study of females aged 50-89 years in the United Kingdom by Menz (22) that used the same footwear assessment tool as our study, reported that compared with women who had worn shoes with a very wide toe-box, the likelihood of HV increased in those who had worn shoes with a narrow $(\mathrm{OR}=2.4 ; 95 \% \mathrm{CI}=1.3$ to 4.4$)$ and very narrow $(\mathrm{OR}=2.7 ; 95 \% \mathrm{CI}=1.5$ to 5.0$)$ toe-box between 20 and 29 years of age, and those who wore shoes with a very narrow toe-box $(\mathrm{OR}=1.9 ; 95 \% \mathrm{CI}=1.1$ to 3.4$)$ between 30 and 39 years of age. There was no association with the self-reported height of the heel of the footwear. Therefore, our findings are in general agreement with Menz (22). It is believed that the use of constrictive shoes may lead to progressive lateral displacement of the hallux by exerting a laterally-directed force against the hallux medial aspect of the hallux (12). However, it is not clear why the fourth decade of life is important. It may be that females spend a greater proportion of time weightbearing in inappropriate footwear during this period. There may also be more complex reasons including changes to foot shape or function during this time period due to changes associated with life events such as pregnancy (38) that amplify the deforming effects of constrictive footwear. It is also possible that a birth cohort effect exists as shown by Menz (22) where females in the United Kingdom born between 1942 and 1952 were more likely than other birth cohorts to wear shoes that had a narrow toebox or high heel when aged in their twenties and thirties. The specificity of our finding for the fourth decade could be in part due to lack of power to detect associations with other

John Wiley \& Sons, Inc.

This article is protected by copyright. All rights reserved. 
decades. There are also likely to be other important environmental or lifestyle factors that are unknown; these could include diet, physical activity or general health.

From the viewpoint of twin study methodology, our finding that the environmental determinant of $\mathrm{HV}$, a narrow or very narrow toe-box in the fourth decade, was substantially correlated for MZ pairs but not correlated for DZ pairs, is noteworthy. The 'equal environments' assumption of the classic twin model assumes that the twin pair correlation for the combined effects of shared environmental effects is the same for MZ pairs as it is for DZ pairs (39). This clearly was not the case for this risk factor. Therefore one cannot presume that the equal environments assumption applies to HV.

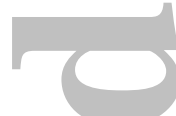

The observation that HV in females is associated with, at least in part, the use of footwear with a constrictive toe-box as the usual footwear during the fourth decade of life has potentially-important clinical implications. Given that footwear choices are modifiable, identification of the most appropriate footwear during the life course may be able to reduce the risk of HV. This argument is supported by the association of reduced prevalence of $\mathrm{HV}$ in males and that men are more likely to wear footwear with a wider toe-box $(2,10,15,40)$. Identification of other modifiable risk factors for HV may aid prevention.

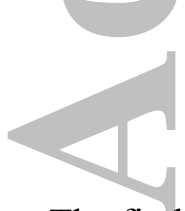

The findings of this study must be interpreted in the context of its limitations. First, the study participants were volunteers registered with the Australian Twin Registry Program, so there was potential for the studied pairs not being sampled independently of their status for HV. However, these women were recruited from the previous study, which investigated genetic 
influences on variation in bone health and balance, unselected for foot pathology (29).

Further, the participation of twins was very high (86\%) for this study. Second, as we used a self-administered questionnaire, we cannot exclude the possibility that some sibling pairs did not complete the questionnaire independently. Also, the use of footwear was based on participant recall. The reliability and validity of the instrument used to determine the selfreported use of footwear across decades is unknown, and could have been influenced by recall bias. However, if recall bias were present we would have expected participants to have also associated their HV with high-heeled footwear, which was not observed. Third, we were unable to examine the effect of footwear or socioeconomic status in childhood, a life stage that has major influence on musculoskeletal development and where there is evidence of incorrectly fitting footwear being associated with HV (41). Additionally, the duration of weightbearing may increase the risk of HV (42), but we do not have the relevant data to examine this possibility. Fourth, we could not ascertain the age of onset of HV. Thus it is possible that earlier onset may have influenced footwear choices. Fifth, HV is a progressive deformity so it is possible that participants classified as not having $\mathrm{HV}$, may develop it in the future. Finally, whilst no effect of genetic factors was identified, and adjustment for toe-box did not reduce the difference in association seen in MZ and DZ twins which was unexpected, the confidence intervals show that the study had limited power. Further studies with larger sample sizes are required to exclude a genetic effect on variation in prevalence.

In conclusion, we confirmed that $\mathrm{HV}$ is a familial condition, but found no evidence that this was due to genetic factors. We also found that the key 'equal environments' assumption of the classic twin model did not apply to a newly-identified risk factor for this condition, bringing into doubt previous estimates of heritability based on that model. Our finding that shared environmental factors are important in the risk of $\mathrm{HV}$, and that the use of footwear

John Wiley \& Sons, Inc. 
with a constrictive toe-box during the fourth decade of life is a specific environmental risk factor, could be particularly important. These findings suggest that HV may be preventable, and the selection of appropriate footwear with a toe-box that is not constrictive may be a useful intervention in future preventative strategies.
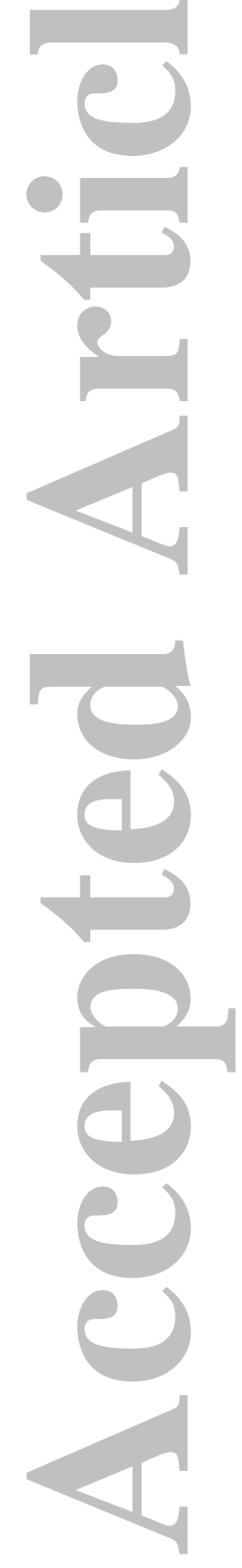

John Wiley \& Sons, Inc. 


\section{REFERENCES}

1. Nix S, Smith M, Vicenzino B. Prevalence of hallux valgus in the general population:

a systematic review and meta-analysis. J Foot Ankle Res. 2010;3:21.

2. Menz HB, Roddy E, Thomas E, Croft PR. Impact of hallux valgus severity on general and foot-specific health-related quality of life. Arthritis Care Res (Hoboken). 2011;63(3):396-

404.

3. Thordarson DB, Ebramzadeh E, Rudicel SA, Baxter A. Age-adjusted baseline data for women with hallux valgus undergoing corrective surgery. J Bone Joint Surg Am.

2005;87(1):66-75.

4. Saro C, Jensen I, Lindgren U, Fellander-Tsai L. Quality-of-life outcome after hallux valgus surgery. Qual Life Res. 2007;16(5):731-8.

5. Lazarides SP, Hildreth A, Prassanna V, Talkhani I. Association amongst angular deformities in Hallux Valgus and impact of the deformity in health-related quality of life.

Foot Ankle Surg. 2005;11(4):193-6.

6. Menz HB, Lord SR. Foot pain impairs balance and functional ability in communitydwelling older people. J Am Podiatr Med Assoc. 2001;91(5):222-9.

7. Mickle KJ, Munro BJ, Lord SR, Menz HB, Steele JR. Gait, balance and plantar pressures in older people with toe deformities. Gait Posture. 2011;34(3):347-51.

8. Tinetti ME, Speechley M, Ginter SF. Risk factors for falls among elderly persons living in the community. N Engl J Med. 1988;319(26):1701-7.

9. Koski K, Luukinen H, Laippala P, Kivela SL. Physiological factors and medications as predictors of injurious falls by elderly people: a prospective population-based study. Age Ageing. 1996;25(1):29-38.

10. Thompson FM, Coughlin MJ. The high price of high-fashion footwear. J Bone Joint Surg Am. 1994;76-A(10):1586-93.

John Wiley \& Sons, Inc.

This article is protected by copyright. All rights reserved. 
11. Thomas S, Barrington R. Hallux valgus. Curr Orthop. 2003;17(4):299-307.

12. Menz HB. Foot Problems in Older People: Assessment and Management. Edinburgh: Churchill Livingstone Elsevier; 2008.

13. Nix SE, Vicenzino BT, Collins NJ, Smith MD. Characteristics of foot structure and footwear associated with hallux valgus: a systematic review. Osteoarthritis Cartilage. 2012;20(10):1059-74.

14. Perera AM, Mason L, Stephens MM. The pathogenesis of hallux valgus. J Bone Joint Surg Am. 2011;93(17):1650-61.

15. Coughlin MJ. Hallux valgus. J Bone Joint Surg Am. 1996;78-A(6):932-66.

16. Frey C. Foot health and shoewear for women. Clin Orthop Relat Res. 2000(372):3244.

17. Dawson J, Thorogood M, Marks SA, Juszczak E, Dodd C, Lavis G, et al. The prevalence of foot problems in older women: a cause for concern. J Public Health. 2002;24(2):77-84.

18. Al-Abdulwahab SS, Al-Dosry R. Hallux valgus and preferred shoe types amongst young health Saudi Arabian women. Ann Saudi Med. 2000;20(3-4):319-21.

19. Menz HB, Morris ME. Determinants of disabling foot pain in retirement village residents. J Am Podiatr Med Assoc. 2005;95(6):573-9.

20. Nguyen US, Hillstrom HJ, Li W, Dufour AB, Kiel DP, Procter-Gray E, et al. Factors associated with hallux valgus in a population-based study of older women and men: the MOBILIZE Boston Study. Osteoarthritis Cartilage. 2010;18(1):41-6.

21. Dufour AB, Casey VA, Golightly YM, Hannan MT. Characteristics associated with hallux valgus in a population-based foot study of older adults. Arthritis Care Res (Hoboken). 2014;66(12):1880-6.

John Wiley \& Sons, Inc.

This article is protected by copyright. All rights reserved. 
22. Menz HB, Roddy E, Marshall M, Thomas MJ, Rathod T, Peat GM, et al.

Epidemiology of Shoe Wearing Patterns Over Time in Older Women: Associations With

Foot Pain and Hallux Valgus. J Gerontol A Biol Sci Med Sci. 2016 pii: glw004. [Epub ahead of print].

23. Hardy RH, Clapham JC. Observations on hallux valgus; based on a controlled series. J Bone Joint Surg Br. 1951;33-B(3):376-91.

24. Mitchell CL, Fleming JL, Allen R, Glenney C, Sanford GA. Osteotomybunionectomy for hallux valgus. J Bone Joint Surg Am. 1958;40-A(1):41-58.

25. Pique-Vidal C, Sole MT, Antich J. Hallux valgus inheritance: pedigree research in 350 patients with bunion deformity. J Foot Ankle Surg. 2007;46(3):149-54.

26. Johnston O. Further studies of the inheritance of hand and foot anomalies. Clin Orthop. 1956;8:146-60.

27. Lee CH, Lee S, Kang H, Jung DE, Song YM, Lee K, et al. Genetic influences on hallux valgus in Koreans: the healthy twin study. Twin Res Hum Genet. 2014;17(2):121-6. 28. Hannan MT, Menz HB, Jordan JM, Cupples LA, Cheng C-H, Hsu Y-H. High heritability of hallux valgus and lesser toe deformities in adult men and women. Arthritis Care Res (Hoboken). 2013;65(9):1515-21.

29. El Haber N, Hill KD, Cassano AM, Paton LM, Macinnis RJ, Cui JS, et al. Genetic and environmental influences on variation in balance performance among female twin pairs aged 21-82 years. Am J Epidemiol. 2006;164(3):246-56.

30. MacInnis RJ, Cassar C, Nowson CA, Paton LM, Flicker L, Hopper JL, et al. Determinants of bone density in 30- to 65-year-old women: a co-twin study. J Bone Miner Res. 2003;18(9):1650-6.

John Wiley \& Sons, Inc.

This article is protected by copyright. All rights reserved. 
31. Young D, Hopper JL, Nowson CA, Green RM, Sherwin AJ, Kaymakci B, et al. Determinants of bone mass in 10- to 26-year-old females: a twin study. J Bone Miner Res. 1995;10(4):558-67.

32. Kasriel J, Eaves L. The zygosity of twins: further evidence on the agreement between diagnosis by blood groups and written questionnaires. J Biosoc Sci. 1976;8(3):263-6.

33. Garrow AP, Papageorgiou A, Silman AJ, Thomas E, Jayson MIV, Macfarlane GJ.

The grading of hallux valgus. The Manchester Scale. J Am Podiatr Med Assoc. 2001;91(2):74-8.

34. Menz HB, Munteanu SE. Radiographic validation of the Manchester scale for the classification of hallux valgus deformity. Rheumatology (Oxford). 2005;44(8):1061-6.

35. Menz H, Fotoohabadi M, Wee E, Spink M. Validity of self-assessment of hallux valgus using the Manchester scale. BMC Musculoskelet Disord. 2010;11(1):215.

36. Roddy E, Myers H, Thomas M, Marshall M, D'Cruz D, Menz H, et al. The clinical assessment study of the foot (CASF): study protocol for a prospective observational study of foot pain and foot osteoarthritis in the general population. J Foot Ankle Res. 2011;4(1):22. 37. Hannah MC, Hopper JL, Mathews JD. Twin concordance for a binary trait. I. Statistical models illustrated with data on drinking status. Acta Genet Med Gemellol (Roma). $1983 ; 32(2): 127-37$.

38. Segal NA, Boyer ER, Teran-Yengle P, Glass NA, Hillstrom HJ, Yack HJ. Pregnancy leads to lasting changes in foot structure. Am J Phys Med Rehabil. 2012;92(3):232-40.

39. Hopper JL. Why 'common environment effects' are so uncommon in the literature. In: Spector TD, Snieder H, MacGregor AJ, editors. Advances in Twin and Sib-pair Analysis. London, UK: Greenwich Medical Media; 1999. p. 151-65.

40. Dufour AB, Broe KE, Nguyen US, Gagnon DR, Hillstrom HJ, Walker AH, et al. Foot pain: is current or past shoewear a factor? Arthritis Rheum. 2009;61(10):1352-8. 
41. Klein C, Groll-Knapp E, Kundi M, Kinz W. Increased hallux angle in children and its association with insufficient length of footwear: A community based cross-sectional study.

BMC Musculoskelet Disord. 2009;10(1):159.

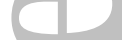

42. Coughlin MJ, Jones CP. Hallux valgus: demographics, etiology, and radiographic
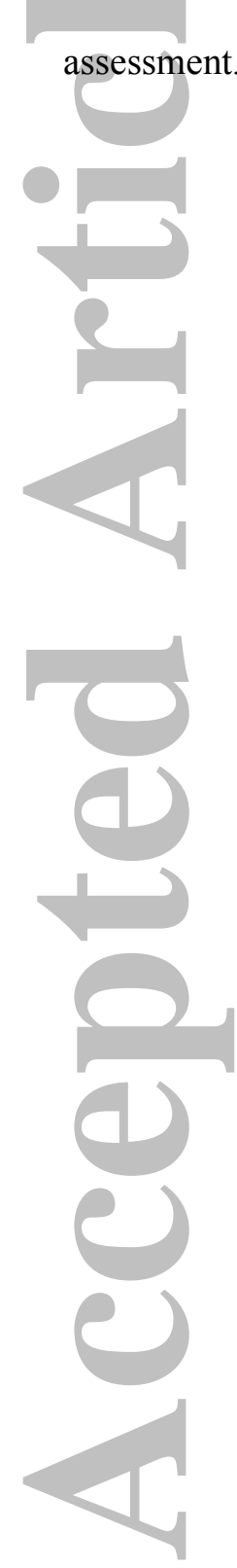

John Wiley \& Sons, Inc. 


\section{TABLES}

Table 1. Characteristics of $M Z$ and $D Z$ twins examined as individual participants.

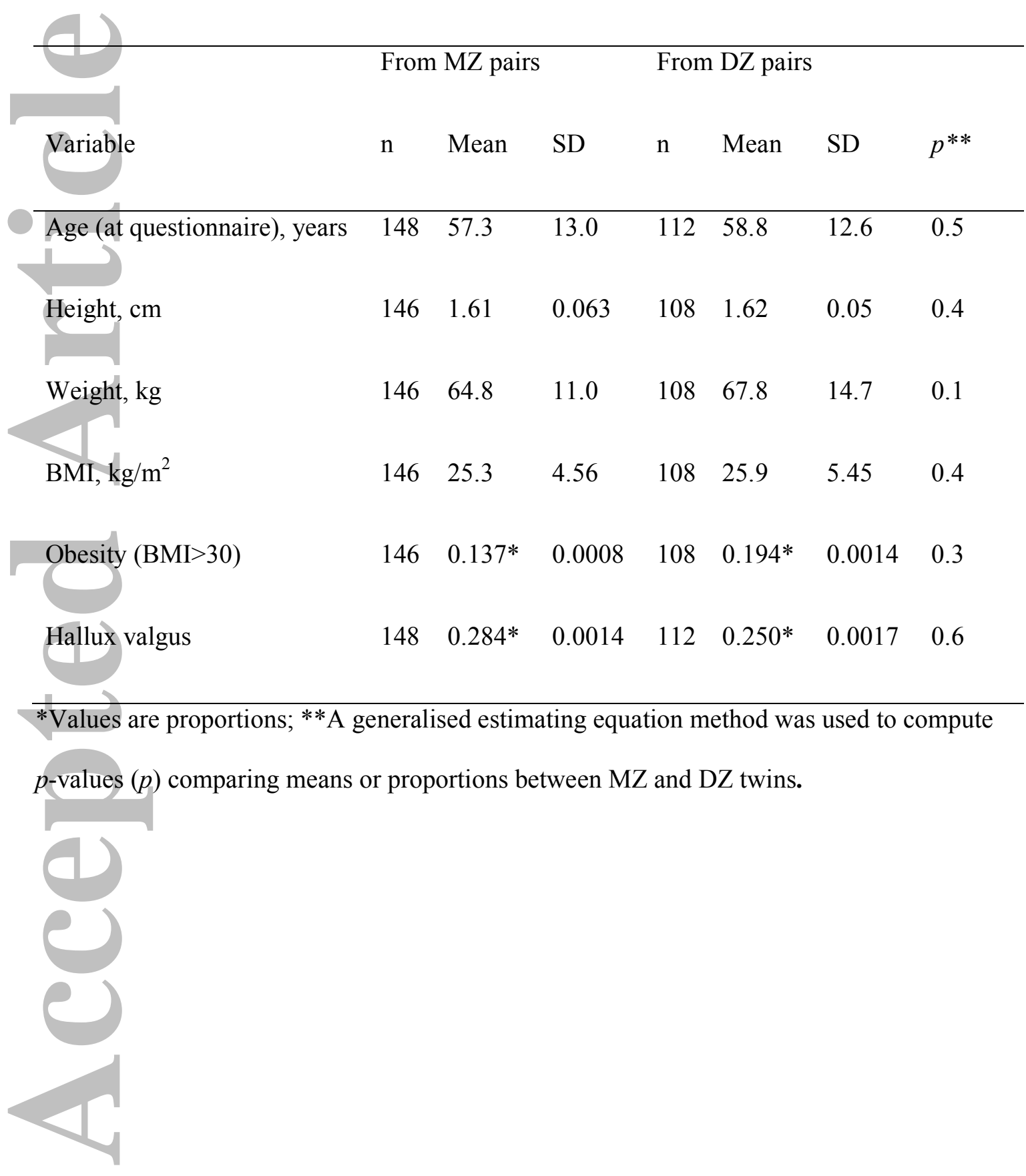

John Wiley \& Sons, Inc.

This article is protected by copyright. All rights reserved. 
Table 2. Simple logistic regression to examine the associations of hallux valgus with inappropriate footwear.

\begin{tabular}{|c|c|c|c|c|c|c|c|c|c|}
\hline 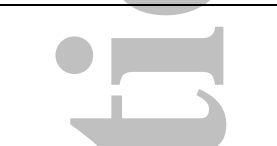 & $\mathrm{MZ}$ & & & DZ & & $\begin{array}{c}P \text {-value for difference in ORs between } M Z \text { and } \\
\text { DZ twins }\end{array}$ & & $\begin{array}{l}\text { Combined } \\
\text { data }\end{array}$ & \\
\hline \multirow{2}{*}{\multicolumn{10}{|c|}{$\begin{array}{l}\text { Use of } \\
\text { inappropri } \\
\text { ate } \\
\text { footwear }\end{array}$}} \\
\hline & & & & & & & & & \\
\hline per & OR $(95 \%$ & & & OR $(95 \%$ & & & & OR $(95 \%$ & \\
\hline decad & CI) & $p$ & $\mathrm{~N}$ & CI) & $p$ & $p$ & $\mathrm{~N}$ & CI) & $p$ \\
\hline \multicolumn{10}{|c|}{ Narrow or very narrow toe-box } \\
\hline & $8.02)$ & & & $5.97)$ & & & & & \\
\hline 30 to 39 & 4.41 & $<$ & 10 & 3.07 & 0.02 & 0.5 & 24 & 3.52 & $<$ \\
\hline 0 & $(2.05$ & 0.001 & 7 & $(1.13$ & 8 & & 7 & $(1.88,6.59)$ & 0.001 \\
\hline & 9.51) & & & $8.31)$ & & & & & \\
\hline
\end{tabular}




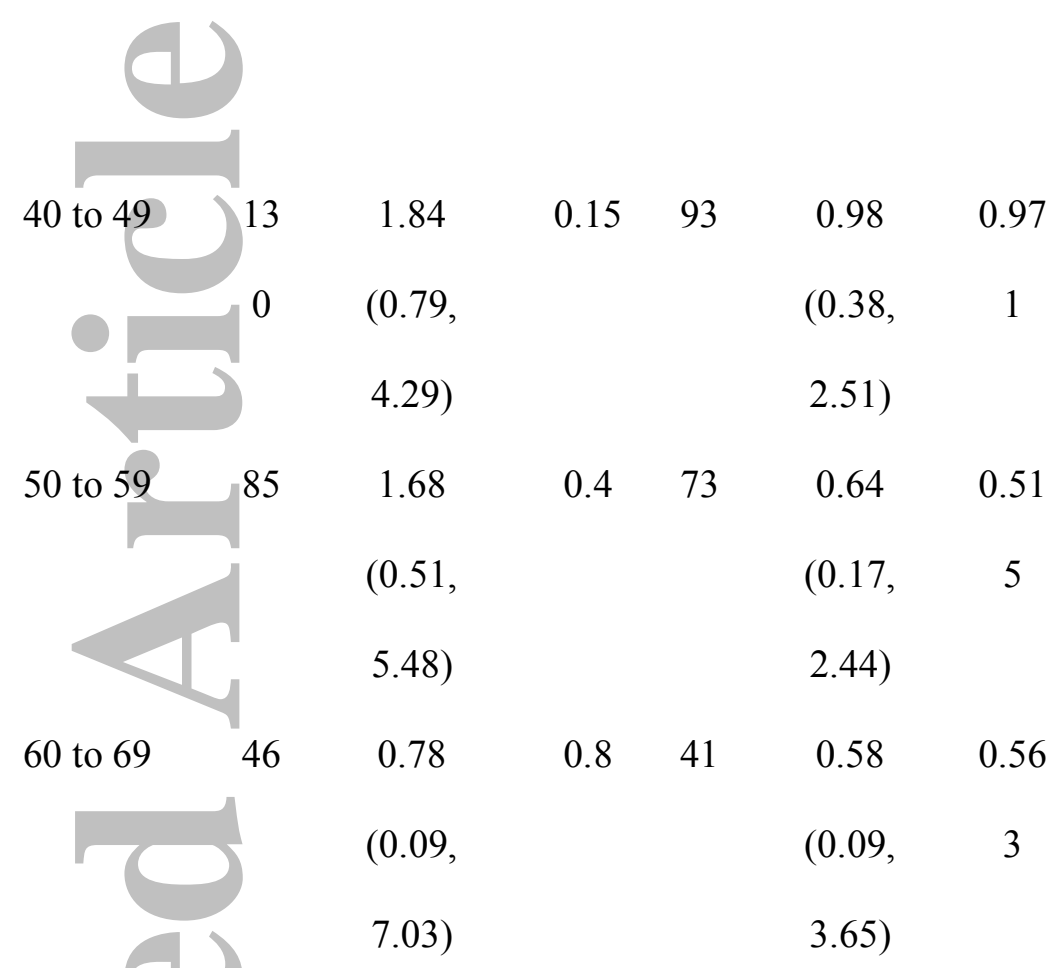

2.97)

30 to $39 \quad 14 \quad 2.24$

(1.06,

4.70)

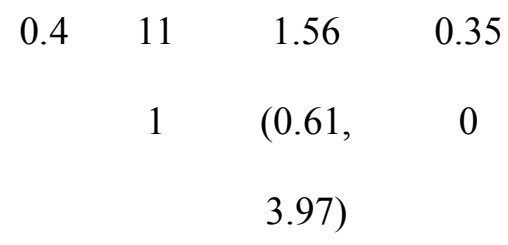

$1 \quad(0.61, \quad 0$

3.97)

$1.84 \quad 0.16$

(0.78, 3

4.32)
0.3

0.8

0.9

$$
\begin{array}{ccc}
22 & 1.43 & 0.259 \\
3 & (0.77,2.65) &
\end{array}
$$

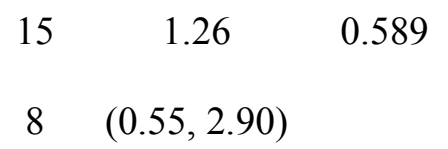




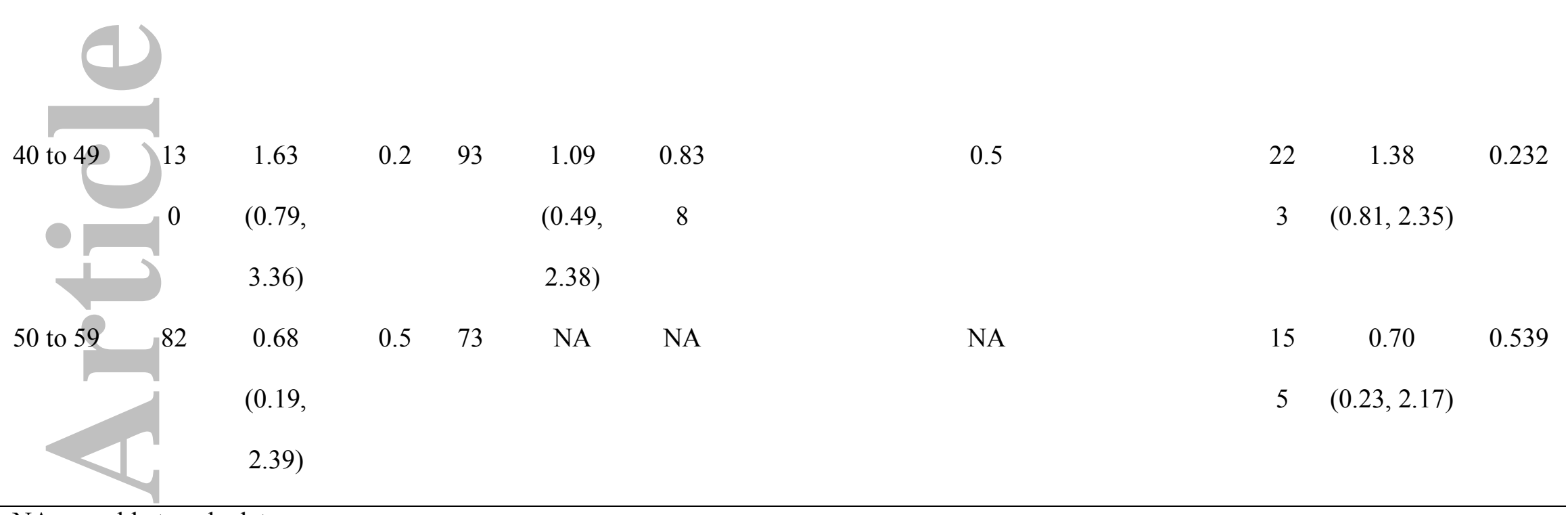

$\mathrm{NA}=$ unable to calculate;

*Insufficient data for analysis of variables toe-box 70 to $79,80+$, as well as heel height 60 to 69,70 to 79 , and $80+$ decades.

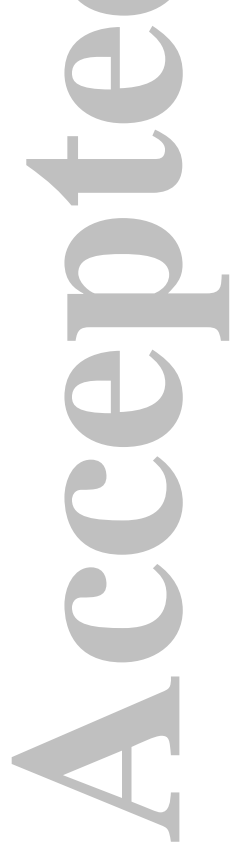


Table 3. Multiple logistic regression to examine the associations of hallux valgus with age, BMI and inappropriate footwear.

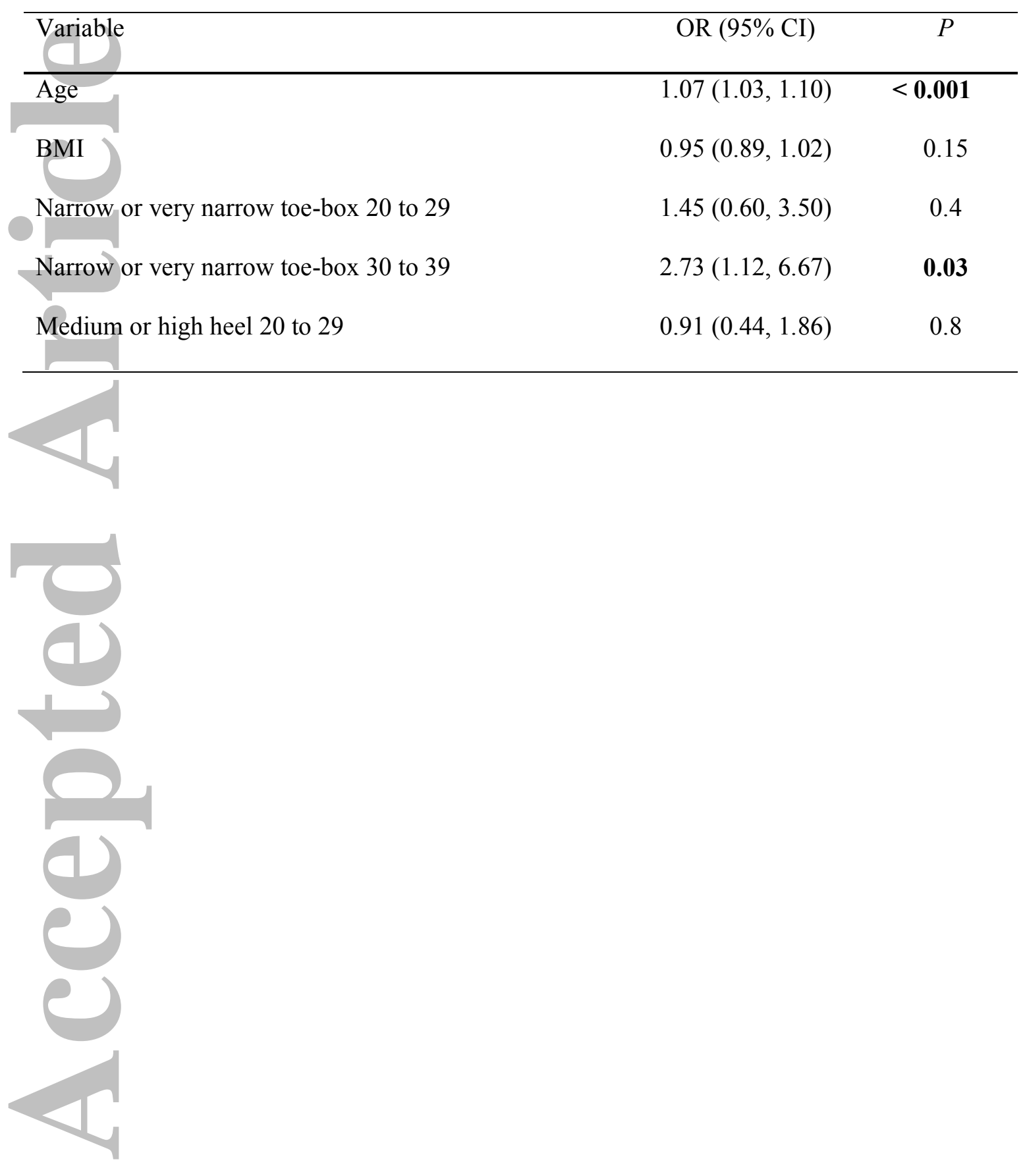

John Wiley \& Sons, Inc.

This article is protected by copyright. All rights reserved. 


\section{FIGURE LEGENDS}

Figure 1. Footwear assessment drawings. Figure from Roddy (36).
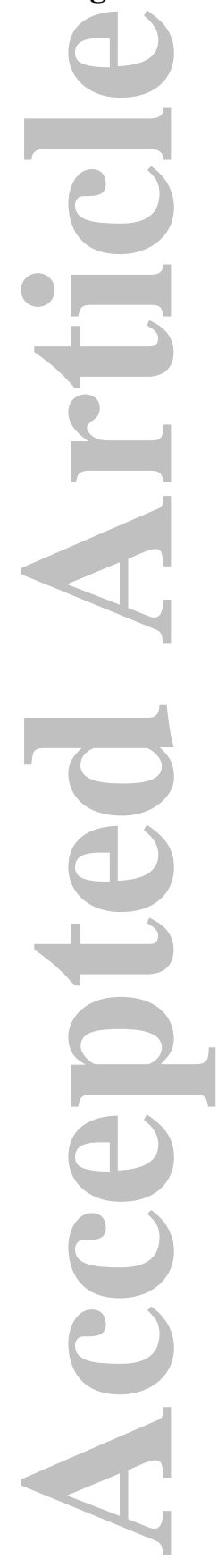

John Wiley \& Sons, Inc.

This article is protected by copyright. All rights reserved. 
heel height

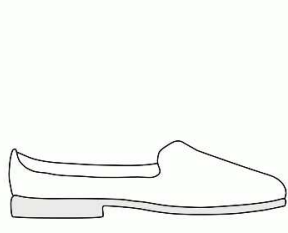

A

toe box shape

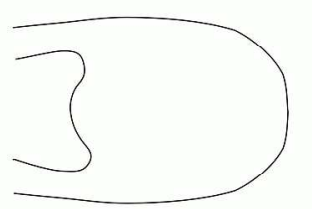

A

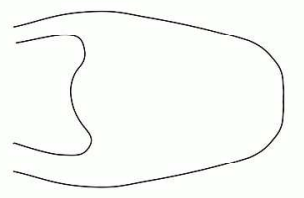

B

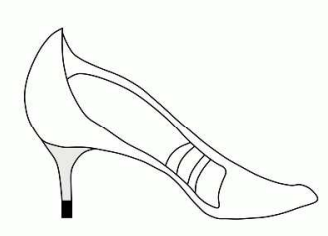

C

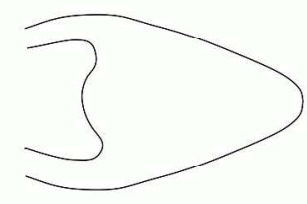

C

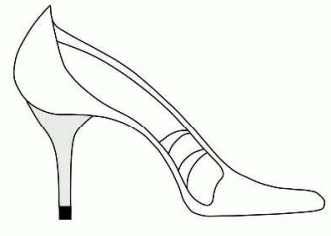

D

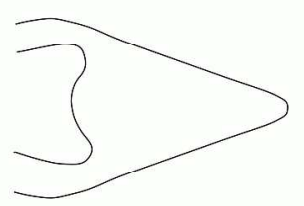

D

Figure 1. Footwear assessment drawings. Figure from Roddy et al. (38). Figure 1

$1539 \times 1054 \mathrm{~mm}(72 \times 72$ DPI $)$

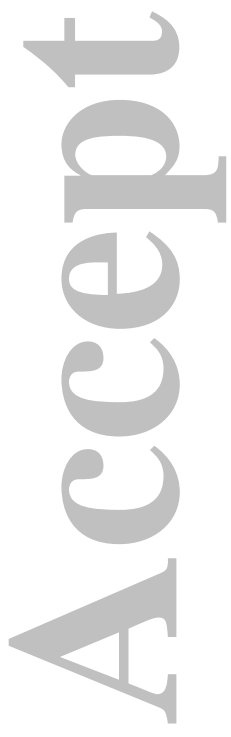

John Wiley \& Sons, Inc.

This article is protected by copyright. All rights reserved. 


\section{University Library}

\section{- M M N E R VA A gateway to Melbourne's research publications}

Minerva Access is the Institutional Repository of The University of Melbourne

Author/s:

Munteanu, SE;Menz, HB;Wark, JD;Christie, JJ;Scurrah, KJ;Minh, B;Erbas, B;Hopper, JL;Wluka, A

Title:

Hallux Valgus, By Nature or Nurture? A Twin Study

Date:

2017-09-01

Citation:

Munteanu, S. E., Menz, H. B., Wark, J. D., Christie, J. J., Scurrah, K. J., Minh, B., Erbas, B., Hopper, J. L. \& Wluka, A. (2017). Hallux Valgus, By Nature or Nurture? A Twin Study. ARTHRITIS CARE \& RESEARCH, 69 (9), pp.1421-1428. https://doi.org/10.1002/acr.23154.

Persistent Link:

http://hdl.handle.net/11343/293320 